Revista Destaques Acadêmicos, Lajeado, v. 11, n. 4, 2019. ISSN 2176-3070

DOI: http://dx.doi.org/10.22410/issn.2176-3070.v11i4a2019.2416

http://www.univates.br/revistas

\title{
DOCUMENTANDO A ARQUITETURA DA IMIGRAÇÃO ALEMÃ NO VALE DO TAQUARI: NOTAS SOBRE O ENXAIMEL EM SANTA CLARA DO SUL/RS ${ }^{1}$
}

\author{
Andressa Carnevalli ${ }^{2}$, Caroline $\mathrm{Nichel}^{3}$, Djulia Marder ${ }^{4}$, \\ Luíze França da Rocha ${ }^{5}$, Jamile Maria da Silva Weizenmann ${ }^{6}$, \\ Jauri dos Santos Sá7
}

\begin{abstract}
Resumo: O texto aqui apresentado constitui desdobramento de pesquisa realizada no âmbito do projeto Para além dos muros: subsídios para (re)descobrir o patrimônio cultural do Vale do Taquari/RS, com vinculação ao projeto de extensão Patrimônio Vivo e ao Escritório Modelo de Arquitetura (EMAU) do curso de Arquitetura e Urbanismo da Universidade do Vale do Taquari - Univates. A arquitetura enxaimel existente no município de Santa Clara do Sul é o objeto de trabalho desta investigação. Ao percorrer as ruas da cidade ou a zona rural do município encontramos diversas edificações que documentam o modo de morar e a técnica construtiva utilizada pelos imigrantes alemães, entre os séculos XIX e XX. Os resultados obtidos permitem avançar com o estudo, o qual tem por foco promover uma consciência transformadora que privilegie o reconhecimento e a valorização do patrimônio cultural presente nas diversas comunidades do Vale do Taquari. Priorizando inventariar a arquitetura enxaimel foi
\end{abstract}

1 Versão completa do resumo expandido apresentado no XXIV Seminário Interinstitucional de Ensino, Pesquisa e Extensão da Universidade de Cruz Alta (Unicruz), realizado em Cruz Alta/RS, nos dias 04 a 07/11/2018. Este texto é resultado de pesquisa realizada com apoio da Universidade do Vale do Taquari - UNIVATES.

2 Arquiteta e Urbanista, Bolsista Voluntária Pesquisa UNIVATES. andressa.carnevalli@universo.univates.br

3 Acadêmica Arquitetura e Urbanismo, Bolsista Extensão UNIVATES. caroline.nichel@univates.br

4 Arquiteta e Urbanista, Bolsista Voluntária Pesquisa UNIVATES. dmarder1@universo.univates.br

5 Acadêmica Arquitetura e Urbanismo, Bolsista Extensão e Pesquisa UNIVATES. luize.rocha@univates.br

6 Dra. em Arquitetura, Docente e Coordenadora Projeto Extensão UNIVATES. jamilew@univates.br

7 Dr. em Arquitetura, Docente e Coordenador Projeto Pesquisa UNIVATES. jauri.sa@univates.br 
utilizado como instrumento de levantamento de dados o modelo de ficha indicado pelo Instituto do Patrimônio Histórico e Artístico do Estado (IPHAE), que abrange diversos itens que identificam e caracterizam as edificações como situação, atuais condições de conservação, características físicas, incluindo levantamento fotográfico e planta baixa. Não estando concluído o levantamento, opta-se por tratar neste artigo sobre os procedimentos metodológicos de documentação dessa arquitetura, tendo como referência um exemplar localizado na zona rural de Santa Clara do Sul.

Palavras-chave: Arquitetura; Enxaimel, Patrimônio; Inventário; Santa Clara do Sul.

\section{INTRODUÇÃO}

Ao abordar a temática da arquitetura, história e patrimônio cultural, bem como da valorização das tradições culturais em comunidades da região Vale do Taquari/RS, será possível incentivar o resgate das memórias locais, que em muito estão ligadas ao processo de colonização. Edificações e manifestações imateriais que representam essas origens ainda estão vivas na região e carecem de atenção, de preservação e de reconhecimento por parte de estudantes, comunidades e entes públicos. Dessa forma, será possível criar condições e oportunidades para que as futuras gerações também se apropriem desse legado cultural, de seus traços identitários, reconhecendo-os coletivamente.

A arquitetura enxaimel existente no município de Santa Clara do Sul é o objeto de trabalho desta investigação. Ao percorrer as ruas da cidade ou a zona rural do município encontramos diversas edificações que documentam o modo de morar e a técnica construtiva utilizada pelos imigrantes, especialmente alemães, entre os séculos XIX e XX. Em recente trabalho (SÁ, WERLE, 2017), construímos um cenário sobre a imigração alemã no qual reforçamos a inserção, entre os séculos XIX e XX, do tipo rural no país.

No âmbito da região do Vale do Taquari, percebe-se muitas das marcas da tradição rural, além de traços da imigração italiana e açoriana. Contudo, muitas informações sobre as tradições imateriais estão se perdendo, não são registradas e a história "contada", por vezes não consegue vencer o tempo. Além disso, as manifestações materiais que revelam características identitárias, como monumentos, edificações e bens tangíveis, também estão em processo de deterioração e descaso.

Os resultados obtidos permitem avançar com o estudo, o qual tem por foco promover uma consciência transformadora que privilegie o reconhecimento e a valorização do patrimônio cultural presente nas diversas comunidades do Vale do Taquari. Não estando concluído o levantamento, opta-se por tratar neste artigo sobre os procedimentos metodológicos de documentação dessa arquitetura, tendo como referência um exemplar localizado na zona rural do município de Santa Clara do Sul. 


\section{POTENCIALIDADES DE UMA FONTE POR INVENTARIAR}

O projeto de pesquisa Para além dos muros: subsídios para (re)descobrir o patrimônio cultural do Vale do do Taquari/RS, tem como objetivo geral promover a construção de instrumentos para possibilitar a compreensão sobre o valor do Patrimônio Cultural nas comunidades do Vale do Taquari. Considerase instrumentos quaisquer elementos que possam gerar subsídio para os estudos, incluindo levantamentos de acervos documentais e de obras, banco digitalizados de imagens, sistematização de informações, interpretação e análise dos fatos, incentivando novas práticas de preservação, salvaguarda e valorização do legado histórico com ênfase nas manifestações arquitetônicas e na valorização da tradição.

Nesse sentido, o patrimônio cultural materializado pelas expressões arquitetônicas e suas interfaces com as mais variadas manifestações (FUNARI e PELEGRINI, 2006), será abordado neste trabalho. Esta é uma abordagem inédita na pesquisa sobre Patrimônio Cultural no Vale do Taquari e servirá para (re)descobrir traços da história local, fortemente atrelado aos processos de povoamento com características da imigração africana ou europeia. No recorte deste trabalho, contempla-se, inicialmente, o município de Santa Clara do Sul, pertencente à microrregião denominada G8 8 .

A cidade foi elencada pois concentra as primeiras atividades de extensão do projeto Patrimônio Vivo. Além disso, a escolha deste município facilita a implementação de atividades de maneira conjunta e integrada, tratando da relação ensino-pesquisa-extensão, por meio da investigação sobre Patrimônio Cultural, recuperando as referências do passado a partir das edificações, especialmente aquelas voltadas aos movimentos migratórios concentrados na segunda metade do século XIX e início do século XX.

Metodologicamenteg o estudo divide-se em etapas, que incluem como instrumentos de coleta de dados a revisão bibliográfica (com vistas à confecção de fichamentos e análise dos dados teóricos levantados), a elaboração de listagem da edificação selecionada, com seu respectivo endereço e ano de construção; levantamento fotográfico (geral e de detalhes construtivos), e o levantamento físico (interno e externo) da edificação; graficação do projeto arquitetônico (plantas de situação e plantas baixas), por meio de programa computacional específico para desenho em arquitetura: AutoCad 2017.

As pesquisas bibliográficas, de campo e imagética são apropriadas para o tipo de dados que se pretende obter. Gil (2002, p. 29), nos recorda que, "a pesquisa bibliográfica é desenvolvida com base em materiais já elaborados, constituídos por livros e artigos científicos, já o estudo de campo é desenvolvido

8 G8, grupo formado pelos municípios de Canudos do Vale, Cruzeiro do Sul, Forquetinha, Sério, Marques de Souza, Progresso, Santa Clara do Sul e Boqueirão do Leão (pertencente ao Vale do Rio Pardo). 
no próprio local onde ocorrem os eventos, na qual seus resultados costumam ser mais fiéis". Por outro lado, essa também é uma pesquisa exploratória, na medida que tem como objetivo proporcionar maior familiaridade com o assunto. Para que isso ocorra, faz-se necessário um processo de sondagem, através de entrevistas e levantamento de dados no local da edificação.

Neste trabalho, os dados teóricos e técnicos foram estudados visando à composição dos fichamentos e a análise das informações. A pesquisa é do estilo ex-post facto, na tradução literal o significado da expressão é "a partir do passado", ou seja, este tipo de pesquisa estuda um evento que já aconteceu (GIL, 2002). As construções no estilo Enxaimel sofreram algumas modificações com o passar do tempo, desde o início da imigração no Brasil, até o século $\mathrm{XX}$, por esse motivo o estudo dessas casas irá determinar quais foram essas variantes, além de determinar o estado atual dessas edificações.

A partir do levantamento e estudo em campo foi elaborado o inventário, produzindo suporte para as conclusões da investigação e sua utilização como instrumento de preservação da arquitetura enxaimel santa-clarense. A entrevista foi realizada com os proprietários da edificação e significa um importante meio de investigação respeito a coleta e análise dos dados. Foram feitos vários questionamentos. Em um primeiro momento, os entrevistados eram informados acerca do trabalho e da importância da preservação das edificações enxaimel. Posteriormente, eram feitas perguntas a respeito da residência, como o ano de construção, características construtivas, tipo de materiais utilizados, ampliações, reformas ou eventuais demolições executadas. E por fim, eram feitos os levantamentos físico e fotográfico da residência.

Para a confecção do inventário, adotou-se o modelo de ficha do Sistema de Rastreamento Cultural utilizada atualmente pelo Instituto do Patrimônio Histórico e Artístico do Estado (IPHAE), que abrange diversos itens que identificam e caracterizam as edificações, como situação, atuais condições de conservação, características físicas, incluindo levantamento fotográfico e planta baixa, uma vez que ela contempla os anseios da pesquisa e fornece as bases para o pleno entendimento dos dados obtidos. Ao eleger o espaço residencial como propósito de investigação, privilegiamos também aspectos como organização, o valor simbólico da edificação e seu diálogo com a comunidade e a sociedade. O Anexo A, apresenta a referente ficha.

Busca-se, assim, o conhecimento geral em torno do universo das construções em enxaimel no Vale do Taquari, identificando exemplares capazes de permitir uma compreensão ampla e representativa daquele momento histórico. No âmbito das técnicas construtivas, buscar-se reconhecer semelhanças com as edificações da arquitetura popular de imigração alemã no sul do Brasil. Nesse aspecto, entende-se que as construções em enxaimel são elementos integrantes deste contexto patrimonial, por meio das quais se podem constituir pontos de interesse turístico relevante, contribuindo para o desenvolvimento sustentável de uma determinada comunidade e/ou região. 


\section{A HABILIDADE CONSTRUTIVA SOB ANÁLISE: A TÉCNICA ENXAIMEL}

Os imigrantes de cultura alemã vieram ao Brasil das mais diversas regiões e por diversos motivos. Originários de territórios como a Renânia (Hunsrück), Pomerânia (região Limítrofe entre a Prússia e a Polônia), e da Vestfália (região meridional saxônica), buscavam no sul do Brasil características semelhantes às da sua região germânica. Conforme Weimer (2005a), na bagagem do imigrante do século XIX, o conhecimento empírico das técnicas da construção em enxaimel, as quais é sabido, com o tempo sofreram ajustes nas formas originais, para melhor adaptação ao clima da região. Na imagem (Figura 1), representação das técnicas construtivas utilizadas nas três principais regiões étnico culturais: Baixa Alemanha (vestfalianos e pomeranos), Média Alemanha (renanos) e Alta Alemanha (bávaros e regiões limítrofes).

Figura 1: Representação das principais técnicas construtivas, segundo as regiões étnico cultural.

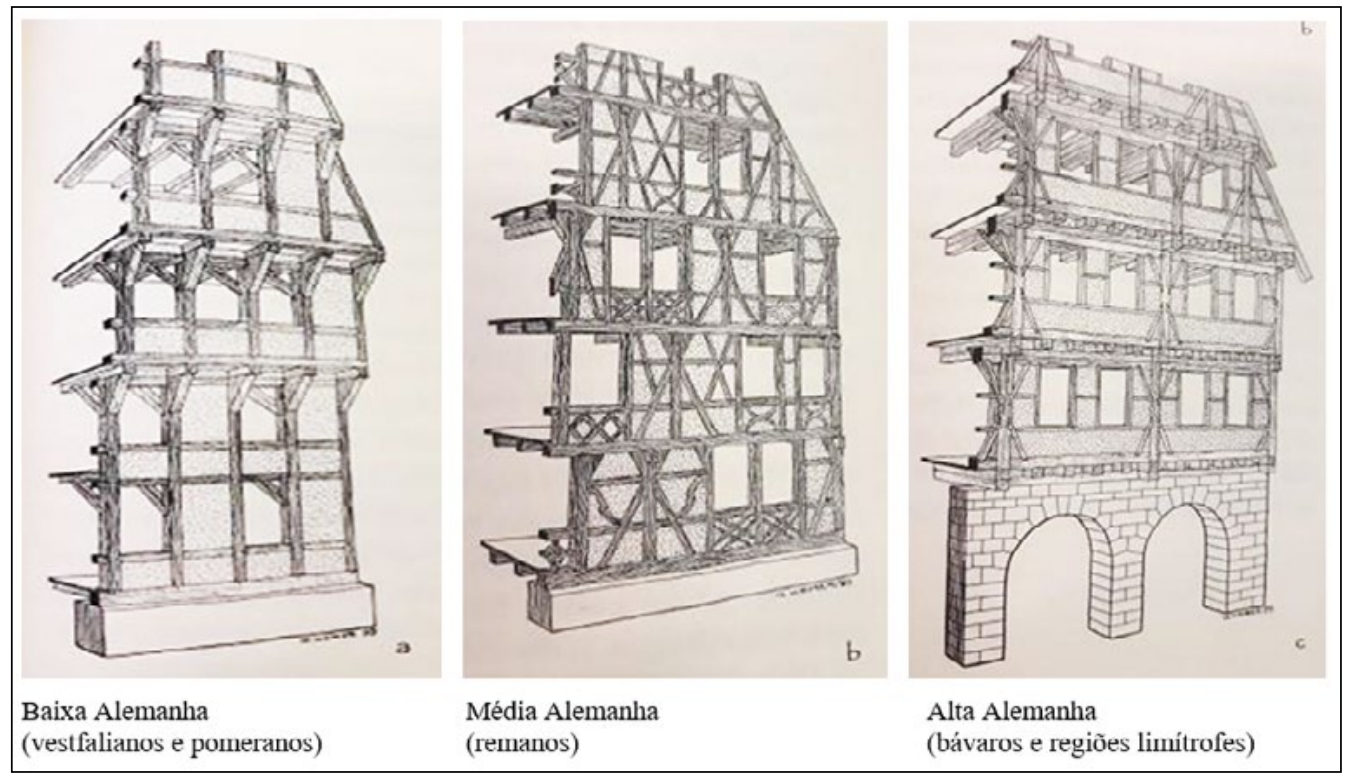

Fonte: (WEIMER, 2005a, p. 162).

O sistema baixo-saxão (baixa Alemanha), foi possivelmente o mais antigo, tendo como características principais o baldrame e os frechais contínuos. Os esteios também eram contínuos e se encaixavam neles. Já os peitoris e vergas eram descontínuos e encaixavam-se nos esteios e as janelas e portas correspondiam aos vãos entre os esteios. As peças inclinadas eram quase que inexistentes, graças à colocação dos contraventamentos, ou seja, eram mãosfrancesas (kopfbänder) encaixadas entre os barrotes. Quando havia panos 
de paredes internas escoradas apareciam os contraventamentos inferiores (Fussbänder) ou cruzes-de-santo-andré. O pé-direito era um pouco mais baixo dos demais sistemas, tendo com frequência a inexistência de vergas nas janelas, quando as casas iam até os frechais (WEIMER, 2005b).

Por outro lado, o sistema alemânico (Alta Alemanha), considerado o mais novo dentro da história, era caracterizado pelo grande afastamento dos esteios principais, exigindo vigamento horizontal mais robusto. Os esteios não eram apoiados nos baldrames e sim diretamente nas fundações. Em sua origem, as extremidades eram enterradas no chão e os baldrames neles encaixados ao nível da terra. Os baldrames eram encaixados por espigas e os frechais muitas vezes eram duplos, em razão dos grandes vãos. O contraventamento (Figura 2) era feito com peças resistentes, na forma de "mulher suaba" (Schwäbisches Weibel), "homem selvagem" (Wilder Mann) e "homem" (Mann). As janelas eram menores e definidas por peitoris e vergas contínuos, encaixados nos esteios principais. As paredes eram mais sóbrias, e o enxaimel era menos trabalhado, e as peças em madeira mais robustas e em menor número. O preenchimento dos tramos eram lisos e caiados, recebendo pinturas murais.

Figura 2: Representação das possibilidades de contraventamento: mulher suaba"; "homem"; "escora" e "cruz de santo andré"; "contraventamento superior e inferior e "homem selvagem", respectivamente.

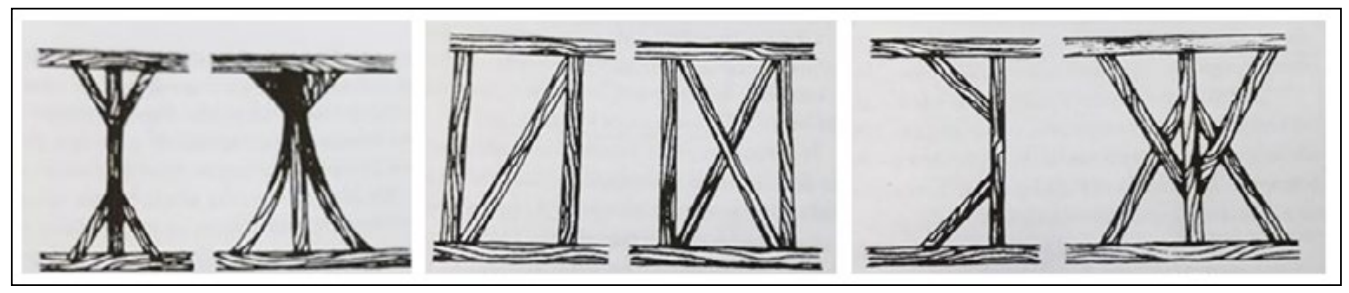

Fonte: (WEIMER, 2005b, p. 71)

Já o sistema franco (Alta Alemanha), tende ao pitoresco, dando valor plástico ao contraventamento e ao fechamento aos tramos. No início as escoras eram retas, e com o passar do tempo passaram a ser curvas, ou foram substituídas pelo "homem selvagem" (Wilder Mann) alemânico, posteriormente sendo executado com peças curvas. Mais tarde, retornou às escoras, que ligavam os baldrames aos cunhais e não mais frechais como no sistema baixosaxão. Na renascença o contraventamento evoluiu para o "homem" (Mann), na qual a escora ia do baldrame ao cunhal. Na altura da verga para cima, entre o cunhal e o flechal, havia um console. A cruz-de-santo-andré recebeu muitas variantes, combinando com peças curvas.

Para fechar os tramos eram colocadas peças transversais, inicialmente duas, passando para quatro, seis, até chegarem a oito. Os construtores procuravam explorar ao máximo a maneira de encaixe, o que remete a certa 
maestria artesanal. A partir da renascença, o frontão passou ser coberto por tábuas perfiladas chamadas de Sose ou Sosse, possivelmente foi a origem da tábua-de-cento (Windbrett) da arquitetura teuto-gaúcha. (WEIMER, 2005b).

Com o passar dos anos os imigrantes alemães passaram a modificar as técnicas construtivas originais para melhor adequação na nova terra. Telles (1977) aborda a organização do espaço aplicado na Alemanha e defende a criação de uma arquitetura própria desenvolvida pelos imigrantes alemães no Brasil, onde a organização do espaço sofreu modificações em um curto período. O contexto em que arquitetura está inserida tem influência direta. A moradia na primeira situação, que é o da Alemanha, se encontrava em um grande espaço de múltiplas atividades. Já no Brasil, a casa que abrigava diversas atividades "explodiu", e cada função passou a receber uma construção própria.

Neste novo quadro, a moradia também sofreu uma ruptura, a casa e a cozinha passaram a ser independentes. Acredita-se que o fogo foi um fator de separação, pelo perigo que representava assim, se a cozinha viesse a queimar a casa seria preservada. A moradia geralmente era construída em um declive do terreno, permitindo a criação de um porão. A organização do espaço era constituída de sala e dois, três ou quatro quartos. O sótão neste contexto serve apenas para guardar velharias, ou ser usado com quarto se a família aumentasse, ou ainda, em eventos como o Kerb (TELLES 1977).

Além dessas modificações feitas em função da topografia e do clima diferente da Alemanha, os imigrantes encontraram outros problemas construtivos, os forçando a encontrar outras soluções. Sendo assim as edificações teuto-gaúchas ganharam características próprias, oriundas das construções teuto-gaúchas.

\section{O OBJETO ARQUITETÔNICO SOB ANÁLISE: A RESIDÊNCIA KRONBAUER}

A arquitetura rural teuto-gaúcha sempre sofreu evoluções para melhor adaptação do imigrante a nova região. As casas constituem-se em qualquer das suas formas, uma combinação original de traços importados e adotados, acrescidos de novos elementos (WEIMER, 2005). A região do Vale do Taquari apresenta muitas casas em estilo enxaimel com variações formais, que possivelmente sejam consequências de influências externas ou da própria dinâmica do processo de adaptação. No município de Santa Clara do Sul localizamos diversos exemplares de residências construídas com a técnica enxaimel (Figura 3). Identificados a partir das ações do projeto de extensão Patrimônio Vivo, essas residências constituem a base para os estudos de caso da pesquisa Para além dos muros: subsídios para (re)descobrir o patrimônio cultural do Vale do do Taquari/RS, as quais serão posteriormente objeto de levantamento técnico. 
Figura 3: Localização das edificações da arquitetura de imigração alemã no município de Santa Clara do Sul. Em laranja a residência da família K., estudo de caso deste trabalho.

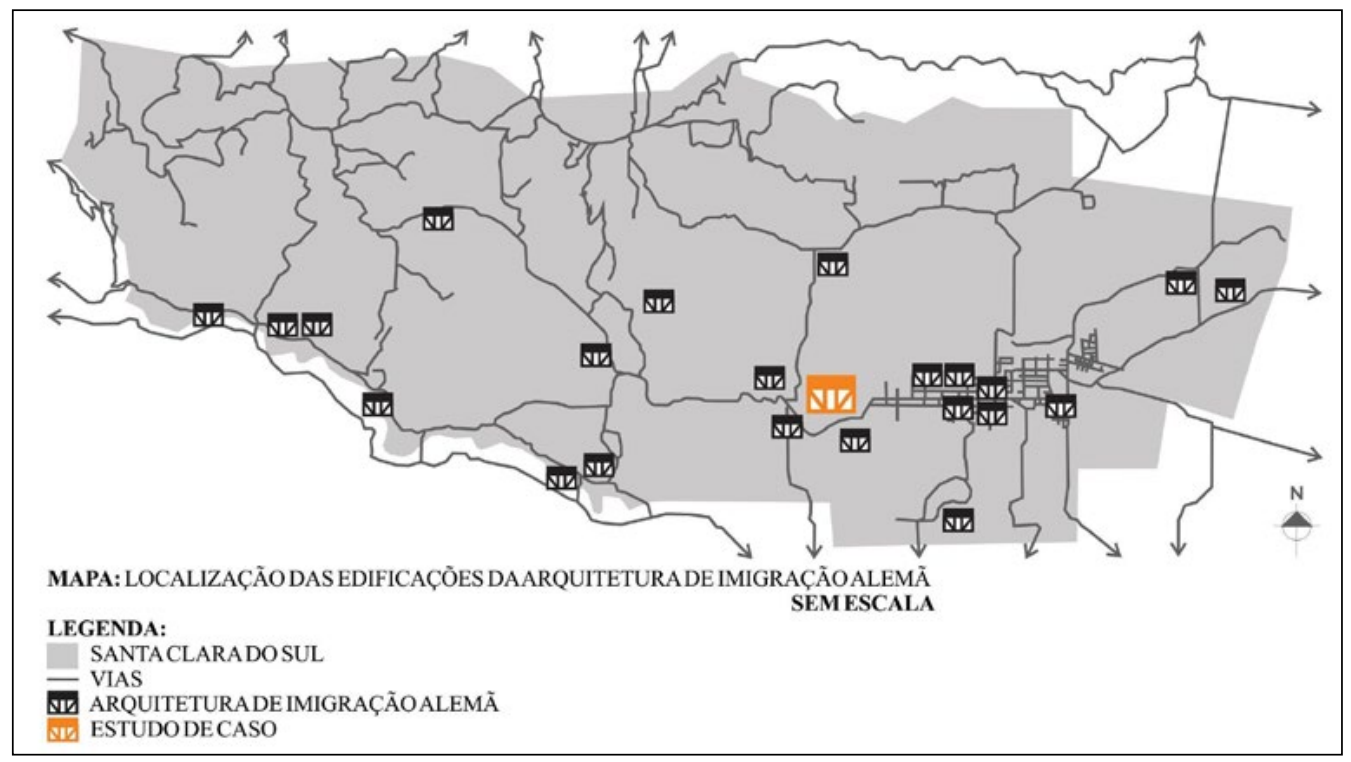

Fonte: Dos autores.

Para este artigo, o objeto de estudo é uma residência localizada próximo ao centro da cidade, de propriedade da família Kronbauer (Figura 4). Composta por duas partes, a primeira possui aproximadamente 165 anos, na qual percebe-se a utilização da técnica construtiva enxaimel. Construída pelo trisavô da proprietária, imigrante alemão, a edificação constitui-se um artefato cultural, que estabelece relação com a história do município. Dentre as particularidades, além do estilo construtivo, há um relato histórico bastante conhecido entre os moradores da cidade. Os proprietários mantêm o vidro de uma das janelas frontais quebrado. Informações obtidas em relatos orais, nos dão conta de que essa singularidade é resultado de um disparo de bala ocorrido durante o confronto da Guerra dos Maragatos, em 1895. Presente na memória da comunidade, a residência se tornou conhecida e, atualmente, 
turmas escolares visitam o local para conhecer a história do município e alguns aspectos respeito a Revolução Federalista9 .

Figura 4: Residência Família Kronbauer, Picada Santa Clara, Santa Clara do Sul/RS (Vista Frontal e Planta Baixa).

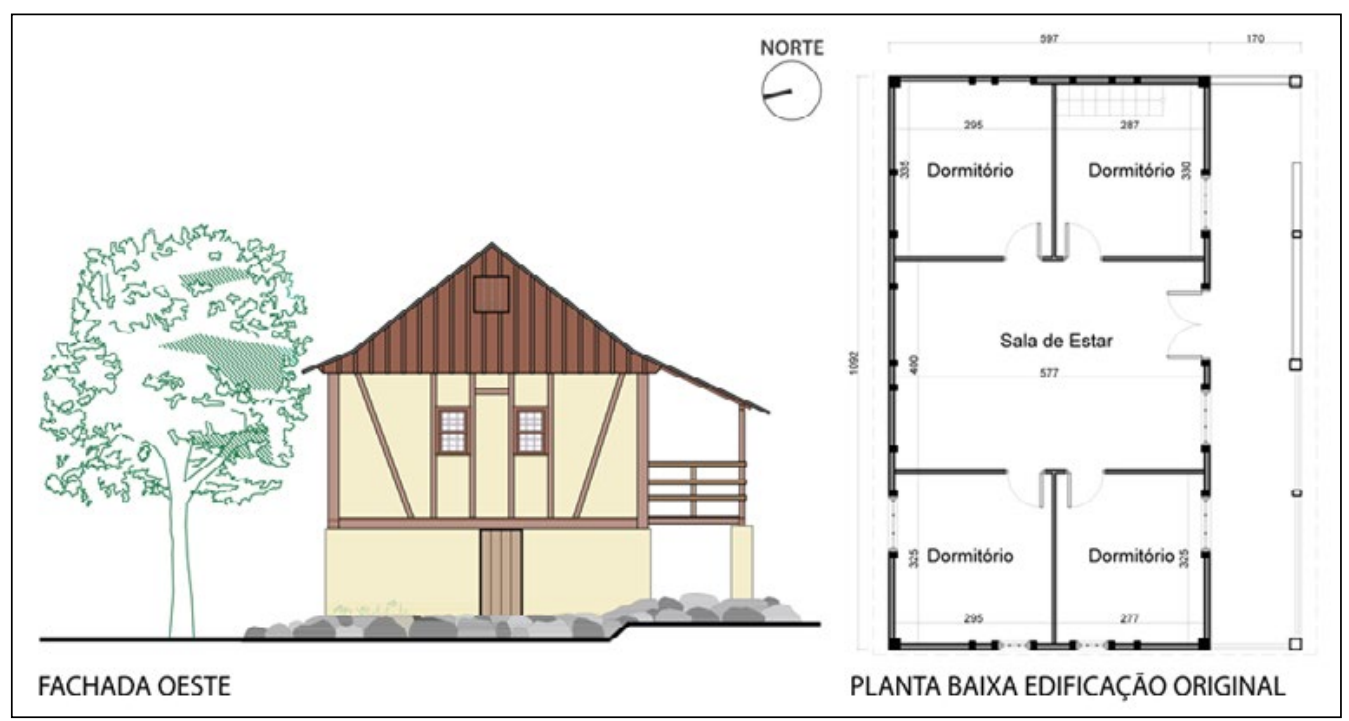

Fonte: Dos autores.

Composta por uma estrutura de madeira, as paredes são preenchidas com alvenaria de tijolos, assentados com barro. Já o porão foi erguido com pedras. A disposição dos ambientes se mantém como original, sendo composta por três dormitórios, uma sala de estar, sótão e porão. A exceção é a cozinha, que originalmente se localizava em uma construção separada, assim como o banheiro. A atual edificação assemelha-se às casas da região de Pomerana, tendo como estrutura o sistema alemânico. Possuindo uma ampliação e consequentemente, apresentando algumas alterações em sua estrutura,

9 “Ao cair da noite do dia 27 de maio de 1895, véspera da invasão de Santa Clara, Zeca Ferreira e seu exército de Maragatos serranos armados, precedentes de Quatro Léguas, atravessaram Sampainho (Nova Berlim), invadindo a propriedade de Marcelus Heisler [...], na localidade de Sampaio, que dita cerca de sete a oito quilômetros de Santa Clara, pela estrada mais próxima. [...]. No dia 28 de maio ainda não amanhecera no horizonte, quando a tropa de Zeca Ferreira deixou a propriedade de Marcelus, em Sampaio, rumo à Picada Santa Clara. A tropa dirigiuse para Santa Clara usando a estrada por "Schusterreck" e, antes do amanhecer do dia, já se encontrava próxima ao Morro do "Löblenberg", atualmente conhecido como "Morro dos Maragatos". Ao avistar a tropa Maragata, naquela manhã, 28 de maio de 1895, a sentinela deu o alarme e os sinais combinados passaram de casa em casa por toda a parte. Os sinos da capela tocaram. Os homens correram para seus postos. Mulheres e crianças correram para o mato, levando consigo o necessário." Para mais informações ver: (CASTRO et al., 2000). 
podendo ser visivelmente percebidas. A partir dos dados inventariados podese efetuar a análise arquitetônico da edificação inventariada.

Conforme Weimer (2005b), as fundações das edificações em enxaimel do Rio Grande do Sul, foram executadas em sua grande maioria com pedra de arenito aparelhada, abundante na maioria das regiões colonizadas por imigrantes. Na edificação apresentada neste trabalho, as fundações foram executadas em pedra de arenito. A edificação da família Kronbauer foi estruturada com pilares de madeira, distribuídos no contorno da edificação. Estas peças atuavam como elementos de descarga da estrutura nas fundações de pedra. $\mathrm{O}$ fato de não estar em contato direto com solo, foi de extrema importância, pois evitou patologias associadas à umidade.

Pode-se afirmar que a edificação analisada segue as características do sistema baixo-saxão, desenvolvido principalmente no norte da Alemanha. $\mathrm{O}$ mais simples dos três sistemas construtivos, suas principais características relacionam-se aos baldrames contínuos. Os esteios, também contínuos, se encaixam nos baldrames e as portas e janelas, nos vãos entre dois esteios. Um detalhe a se destacar é a não utilização de pregos ou parafusos para a fixação das peças da estrutura enxaimel, assim como outras peças como o forro, piso, esquadrias e eventuais escadas. Na residência Kronbauer também se observa que o contraventamento, elemento responsável por proporcionar rigidez e estabilidade a estrutura, foi executado na forma de escora. As peças de madeira ficam aparentes e foram pintadas com uma cor mais escura.

O preenchimento dos tramos do enxaimel foi executado com tijolos maciços de barro cozido. É provável que os tijolos tenham sido executados de maneira rústica e artesanal, pelos próprios proprietários, no local da obra. $\mathrm{O}$ reboco dos tramos também foi executado com barro. Apenas as partes mais novas (anexos) e o novo revestimento do porão, foram executados com reboco de cimento. As esquadrias são de madeira, material abundante na época da construção. Alguns ambientes, mais novos, possuem esquadrias metálicas. O telhado inclinado é outra característica marcante na arquitetura enxaimel. $\mathrm{Na}$ residência Kronbauer permitia o aproveitamento como sótão, utilizado inicialmente para estocagem de alimentos. O telhado a duas águas foi finalizado com telhas metálicas de zinco, o qual ainda apresenta a cobertura original.

Respeito a distribuição dos ambientes a residência Kronbauer pode ser classificada como um exemplar típico da imigração alemã no Rio Grande do Sul, ou seja, apresenta dois pares de quartos nas extremidades e uma sala centralizada. O acesso a sala ocorre pela lateral, através de uma varanda. A sala hoje é um espaço mais reservado e o hábito de reunir a família acontece na cozinha e na varanda, especialmente nos dias de verão.

A cozinha está localizada em uma edificação anexa ao corpo principal. A ampliação realizada para abriga-la incluiu um banheiro e aconteceu prolongando-se as águas do telhado no sentido longitudinal. Após algumas reformas, hoje está executada em alvenaria rebocada com cimento. No pátio 
são encontradas construções independentes, como galpão para máquinas, estábulo etc. A residência, cercada por horta e pomar, apresenta bom estado de conservação, pois percebe-se que recentemente foram pintadas as esquadrias e a própria estrutura.

\section{ALGUMAS CONSIDERAÇÕES}

O trabalho, ainda em andamento, está sendo realizado a partir do projeto de pesquisa Para além dos muros: subsídios para (re)descobrir o patrimônio cultural do Vale do do Taquari/RS, vinculado ao curso de Arquitetura e Urbanismo da Univates. É objetivo que estas ações possam contribuir para o desenvolvimento de projetos que permitam a valorização do patrimônio cultural, despertando a consciência das comunidades do Vale do Taquari, respeito a importância da preservação da identidade arquitetônica dos municípios.

Santa Clara do Sul, município objeto de estudo neste trabalho, possui um número significativo de exemplares construídos a partir da técnica do enxaimel, revelando uma possível rota cultural teuto-alemã (Ver Figura 3). São edificações que apresentam a técnica construtiva similar as oriundas da região da Pomerânia (WEIMER, 2005b). A edificação analisada neste artigo foi escolhida devido a sua importância histórica local, vinculados à Guerra dos Farrapos. Sua estrutura em madeira assemelha-se ao sistema baixo-saxão (baixa Alemanha), tendo como características principais o baldrame e os frechais contínuos, demonstrando a similaridade com as construções mais simples e antigas da Alemanha.

A catalogação das edificações em enxaimel no município de Santa Clara do Sul, além de permear o seu contexto histórico, tem condições de atuar como instrumento de políticas públicas, seja respeito a sua preservação, seja como ação voltada a economia local. Nesse sentido, o inventário interdisciplinar torna-se uma ferramenta efetiva para esse propósito. É intenção do projeto de pesquisa disponibilizar a comunidade local, a Prefeitura Municipal e as escolas do município, o registro produzido. Portanto, é de fundamental importância dar seguimento às ações de levantamento e catalogação das residências em enxaimel, contribuindo para a preservação dos bens de interesse arquitetônico, histórico e cultural remanescentes no território santa-clarense.

\section{REFERÊNCIAS}

CASTRO, Carmem Lúcia Weber; PADOIN, Maria Medianeira. A revolução federativa em Santa Clara do Sul: um estudo de caso (1893-1895). Disciplinarum Scientia, Série Ciências Sociais e Humanas. Universidade Franciscana, Santa Maria/RS. Vol. 1, n. 1, 2000, p. 144-155. Disponível em: <https://periodicos.ufn.edu.br/index.php/ disciplinarumCH/article/view/1575/1480>. Acesso em: 20 out. 2019. 
FUNARI, Pedro Paulo; PELEGRINI, Sandra C. A. Patrimônio Histórico e Cultural. 1. ed. Rio de Janeiro: Zahar, 2006.

GIL, Antonio Carlos. Como elaborar projetos de pesquisa. São Paulo: Editora Atlas S.A., 2002

SÁ, Jauri dos Santos; WERLE, Flavia Obino Correa. Imigrantes eruditos e a sua contribuição para a arquitetura escolar gaúcha: notas de investigação. In: Tiago Weizenmann, Rodrigo Luís dos Santos, Caroline von Mühlen (Org.). Migrações históricas e recentes. 1ed. Lajeado: Editora da Univates, 2017, v. 1, p. 129-143. Disponível em: <https:/ / www.univates.br/editora-univates/media/ publicacoes/209/pdf_209.pdf>. Acesso em: 20 out. 2019.

WEIMER, Günter. Arquitetura erudita da imigração alemã no Rio Grande do Sul. Porto Alegre: Edições EST, 2004.

WEIMER, Günter. Arquitetura Popular Brasileira. São Paulo: Martins Fontes, 2005a.

WEIMER, Günter. Arquitetura Popular da Imigração Alemã. $2^{a}$ ed. Porto Alegre: UFRGS, 2005b. 